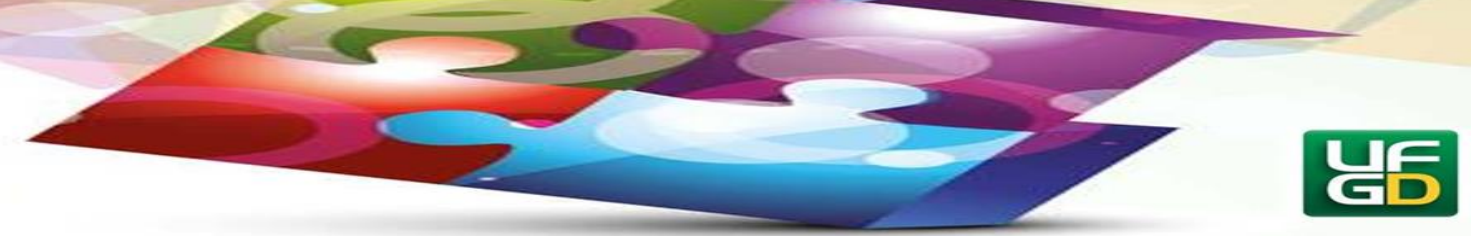

\title{
FUNÇÃO TANGENTE: DESENVOLVENDO ESSE TIPO DE FUNÇÃO COM A MODELAGEM MATEMÁTICA
}

TANGENT FUNCTION: DEVELOPING THIS TYPE OF FUNCTION WITH

MATHEMATICAL MODELING

Felipe de Almeida COSTA ${ }^{1}$

Marcio Vieira de ALMEIDA ${ }^{2}$

\begin{abstract}
Resumo: no presente artigo é apresentada uma sequência didática em que é objetivado que os alunos, a partir de dados obtidos pelo comprimento da sombra de uma haste no decorrer do dia em relação a posição do sol, sistematizassem uma função periódica: a função tangente. Essa sequência foi aplicada em uma turma de $3^{\circ}$ ano do Ensino Médio. A atividade foi conduzida pelo primeiro autor deste trabalho que também é professor da turma. Utilizou-se como metodologia a observação participante em que o pesquisador faz intervenções de modo que os alunos pudessem interagir significativamente com as atividades presente na sequência. A sequência foi desenvolvida com o auxílio da teoria da aprendizagem significativa, nesse sentido, nas atividades buscava-se relacionar os conhecimentos prévios dos estudantes (movimento periódico) ao novo conhecimento (função tangente). Para a obtenção dos dados utilizamos os pressupostos da Modelagem Matemática, pois os alunos analisavam o fenômeno relacionado à medida do comprimento da sombra da haste e registravam essas medidas e, com esses valores em mãos, realizavam as atividades da sequência. Com a realização da sequência foi evidenciado que a Modelagem Matemática com a Teoria da Aprendizagem Significativa foi capaz de levar o aluno a uma aprendizagem significativa acerca do conhecimento da função trigonométrica tangente.
\end{abstract}

Palavras-chave: Modelagem Matemática. Aprendizagem Significativa. Função Tangente.

Abstract: the present article presents a didactic sequence in which it was proposed that the students based on data obtained by the length of the shade of a rod in the course of the day in relation to the position of the sun systematized a periodic function in the case the tangent function. This sequence was applied to a 3rd-grade high school class, and they were arranged in groups. The activity was conducted by the first author of this work who is also the teacher of the class. Participant observation was used as the methodology in which the researcher made interventions so that the students could interact significantly with the activities present in the sequence. The sequence was developed with the help of the theory of meaningful learning, in that sense, the activities sought to relate students' previous knowledge (periodic movement) to new knowledge (tangent function). In order to obtain the data, we used the assumptions of

\footnotetext{
${ }^{1}$ Doutorando em Ensino de Ciências e Matemática pela Universidade Cruzeiro do Sul (UNICSUL). E-mail: felipeacosta@prof.educacao.sp.gov.br

${ }^{2}$ Doutor em Educação Matemática pela Pontifica Universidade Católica (PUC) de São Paulo. E-mail: marcioalmeidasp@gmail.com
} 


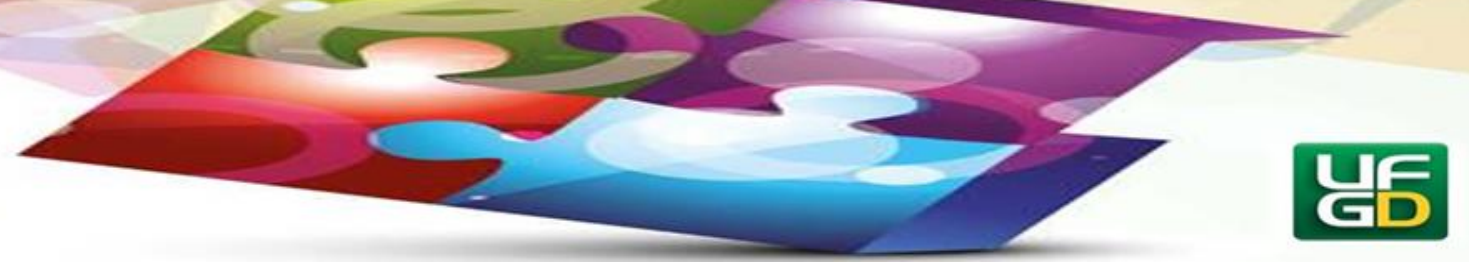

Mathematical Modeling, since the students analyzed the stem shade phenomenon and recorded these values, and with these values, in hand, they performed the sequence activities. With the accomplishment of the sequence, it was evidenced that the mathematical modeling with the theory of the significant learning was able to take the student to a significant learning about the knowledge of the tangent trigonometric function.

Keywords: Mathematical Modeling. Significant Learning. Tangent Function.

\section{Introdução}

A sequência didática disposta neste trabalho foi desenvolvida com o objetivo de conduzir os alunos a um aprendizado com significado ${ }^{3}$ da função tangente, o intuito era fazer com que eles percebessem a existência de funções periódicas e que elas estão presentes no nosso dia a dia.

A sequência é constituída por oito atividades, em que sua realização dependia de dados obtidos pelos alunos, a partir deles os alunos realizavam cada atividade e com o objetivo de desenvolver o conceito de função periódica pelo estudo da função tangente. Essa sequência foi realizada uma turma de $3^{\circ}$ ano do Ensino Médio de uma Escola Pública de São Paulo, com 25 alunos em que os mesmos foram dispostos em grupos de cinco alunos, cabe ressaltar que o primeiro autor deste artigo é professor da turma.

A pesquisa foi desenvolvida tomando-se por referência constructos teóricos da Teoria da Aprendizagem Significativa. Assim sendo foram admitidos como conceitos subsunçores dos alunos, os fenômenos periódicos e conhecimentos básicos ${ }^{4}$ de funções, conforme Ausubel esses conceitos são necessários para a construção do novo conhecimento.

A partir da nossa prática, percebemos que os alunos sentem dificuldades para assimilar os conceitos de funções trigonométricas, em especial a função tangente. Nesse sentido, utilizamos nessa pesquisa a Modelagem Matemática, pois ela permite que o aluno verifique conceitos matemáticos presentes na natureza, nosso caso, o comprimento da sombra de uma haste no decorrer de dois dias. Dessa forma com a Modelagem Matemática objetivava-se organizar os conceitos que seriam trabalhados, ou seja, a sequência desenvolvida a partir dos

\footnotetext{
${ }^{3}$ Esse termo no âmbito da Teoria da Aprendizagem Significativa de Ausubel.

${ }^{4}$ Entendemos por conhecimentos básicos perceber domínio e imagem da função e conseguir criar um sistema cartesiano com os valores de $\mathrm{f}(\mathrm{x})$ e $\mathrm{x}$.
} 


\section{HORIZONTES - REVISTA DE EDUCACÃ̃O}

e-ISSN: 2318-1540

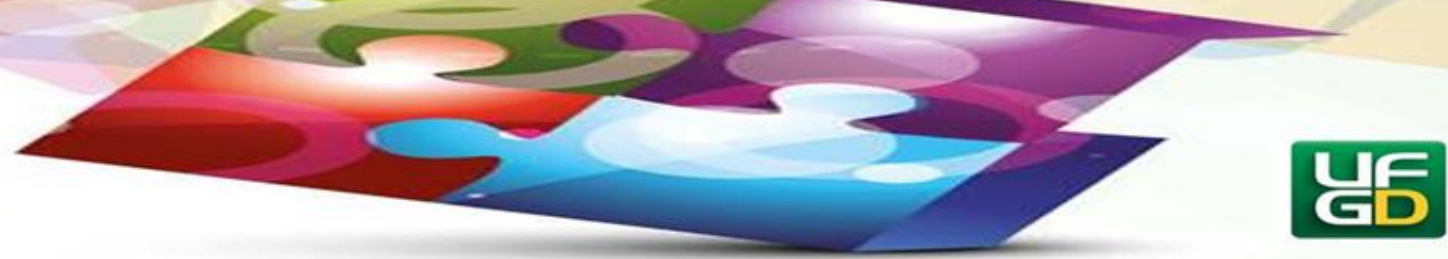

pressupostos da Modelagem Matemática pretende ser o organizador prévio do conhecimento dos alunos.

Em relação a trigonometria o PCN indica: "Devemos observar que uma parte importante da Trigonometria diz respeito às funções trigonométricas e seus gráficos" (BRASIL, 1998, p. 43).

Esse documento explicita também que:

[...] a relação da aprendizagem de Matemática com o desenvolvimento de habilidades e competências e a Trigonometria, desde que seu estudo esteja ligado `as implicações, evitando-se o investimento excessivo no cálculo algébrico das identidades e equações para enfatizar os aspectos importantes das funções trigonométricas e da análise de seus gráficos. Especialmente para o indivíduo que não prosseguirá seus estudos nas carreiras ditas exatas, o que deve ser assegurado são as aplicações da Trigonometria na resolução de problemas que envolvam medições, em especial o cálculo de distâncias inacessíveis, e na construção de modelos que correspondam a fenômenos periódicos. Nesse sentido, um projeto envolvendo também a Física pode ser de grande oportunidade de aprendizagem significativa (BRASIL, 1998, p. 44).

Nesse sentido, no PCN é ressaltada a importância de os alunos terem contatos com funções trigonométricas e, em especial, os seus gráficos e consigam relacionar os mesmos a fenômenos periódicos presentes na natureza.

Já a BNCC em relação a trigonometria, apresenta a seguinte habilidade:

Identificar as características fundamentais das funções seno e cosseno (periodicidade, domínio, imagem), por meio da comparação das representações em ciclos trigonométricos e em planos cartesianos, com ou sem apoio de tecnologias digitais (BRASIL, 2017, p. 529).

Assim entendemos que nosso estudo pode fornecer contribuições para estudo das funções periódicas, pois, com as atividades desenvolvidas, os alunos conseguem perceber, de que forma aparecem em fenômenos periódicos e a importância de se estudar esse tipo de função.

O trabalho de Costa (2017) apresenta um estudo das funções trigonométricas seno e cosseno a partir de um fenômeno periódico, o índice pluviométrico, nesse estudo também é utilizada a Modelagem Matemática. O autor ressalta que a ação de modelar o fenômeno foi eficaz, pois os alunos perceberam a importância desse estudo. Do mesmo modo buscamos com que os alunos percebessem a importância da função tangente.

A partir do exposto, buscamos na bibliografia dissertações e teses que utilizaram a Modelagem Matemática para auxiliar no ensino de funções trigonométricas e o que os autores 


\section{HORIZONTES - REVISTA DE EDUCAÇÃO}

e-ISSN: 2318-1540

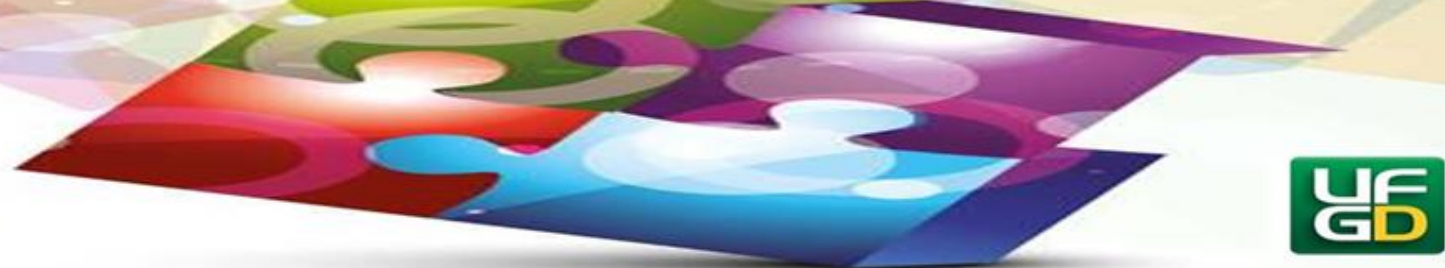

apresentam em relação ao uso dessa estratégia para o ensino. Na próxima seção traremos essas discussões.

\section{Revisão Bibliográfica}

A revisão bibliográfica é parte essencial de uma pesquisa, pois possibilita a conversa com os pesquisadores que já investigaram o mesmo assunto e contribui com o avanço científico. Na pesquisa apresentada nesse artigo, a revisão foi feita como segue:

Primeiramente foi feito uma busca no banco de teses da CAPES $^{5}$ com as palavraschaves "funções periódicas e funções trigonométricas", encontrando 27404 registros. Em razão do número foi refinada a busca para dissertações e teses, das áreas de concentração: educação, matemática e educação matemática.

Com esse refinamento resultaram 545 trabalhos. Com o foco acerca do ensino dessas funções, chegou-se a um total de 22 trabalhos ${ }^{6}$ que tratavam desse ensino, sendo que os mesmos utilizavam diversas estratégias que foram caracterizadas da seguinte forma:

Quadro 1: Caracterização das dissertações analisadas
\begin{tabular}{|l|c|}
\hline Utilizam como estratégias & Quantidade \\
\hline GeoGebra & 12 \\
\hline Modelagem Matemática & 2 \\
\hline Uso de Materiais* & 2 \\
\hline Sequência didática & 3 \\
\hline Outro Software & 4 \\
\hline Fenômenos Físicos & 5 \\
\hline Resolução de Problemas & 7 \\
\hline Uso de livros didáticos & 2 \\
\hline
\end{tabular}

Fonte: Produção nossa

*Estratégias que usam alguma ferramenta criada pelo autor do trabalho pesquisado.

\footnotetext{
${ }^{5}$ Coordenação de Aperfeiçoamento de Pessoal de Nível Superior.

${ }^{6} \mathrm{Na}$ Tabela 1 estão apresentadas as estratégias utilizadas nesses trabalhos, sendo que alguns apresentam mais de uma estratégia, elas não são disjuntas
} 


\section{HORIZONTES - REVISTA DE EDUCAÇÃO}

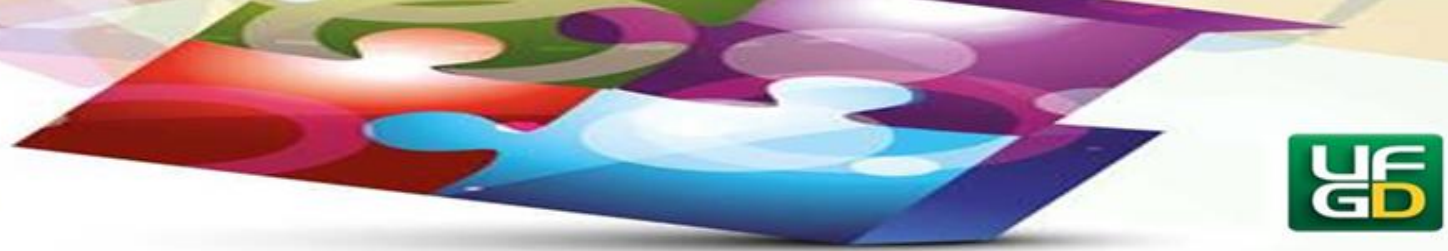

Dentre os cinco que utilizaram fenômenos físicos para a introdução do conceito de função trigonométrica. Selecionamos dois trabalhos (SANTOS, 2014; COSTA, 2017) que utilizaram pressupostos da Modelagem Matemática, como a proposta da pesquisa relatada neste artigo. No trabalho de Santos (2014) foi utilizado o material oficial do Estado de São Paulo e o fenômeno estudado foi o movimento do sol durante as estações do ano, que pode ser modelado pela função seno. Ainda foi considerada a diferença do comprimento de uma sombra no equinócio e no solstício e a partir dessa diferença de comprimento é possível modelar a função seno. No trabalho de Costa (2017) apresentou o índice pluviométrico de uma cidade e as atividades desenvolvidas tinham por objetivo fazer com que o aluno pudesse perceber que esse fenômeno é periódico, após isso foi modelado o movimento de uma bolinha presa a uma roda de bicicleta e a partir desse movimento é trabalhado as razões seno e cosseno, assim são apresentado modelos que pode ser modelados por essas funções.

Em ambos os trabalhos percebemos que a Modelagem Matemática foi um facilitador para o ensino das funções, assim podemos concluir que essa estratégia pode contribuir para uma aprendizagem significativa.

Também a partir da fonte pesquisada (banco de teses da CAPES) percebemos que faltam pesquisas que tratem das funções trigonométricas com o uso da modelagem e que a função tangente não foi contemplada nas dissertações e teses. Na próxima seção apresentaremos o procedimento metodológico utilizado para produção deste trabalho.

\section{Procedimentos Metodológicos}

A pesquisa apresentada é de natureza qualitativa, ou seja, buscamos interpretar o fenômeno pesquisado o observando com profundidade no sentido de analisar o processo como um todo. Goldenberg (2007) entende que a pesquisa qualitativa não se preocupa com a implantação de leis para a pesquisa, mas com a compreensão aprofundada dos dados pesquisados.

Para a obtenção dos dados utilizamos a observação participante, nesse modelo de pesquisa o pesquisador se insere no ambiente pesquisado buscando as ações mais fidedignas que aparecem no meio da pesquisa. Para Wilkinson (1995): i) possibilita a entrada a determinados acontecimentos que seriam privativos e aos quais um observador estranho não 


\section{HORIZONTES - REVISTA DE EDUCACÃ̃O}

e-ISSN: 2318-1540

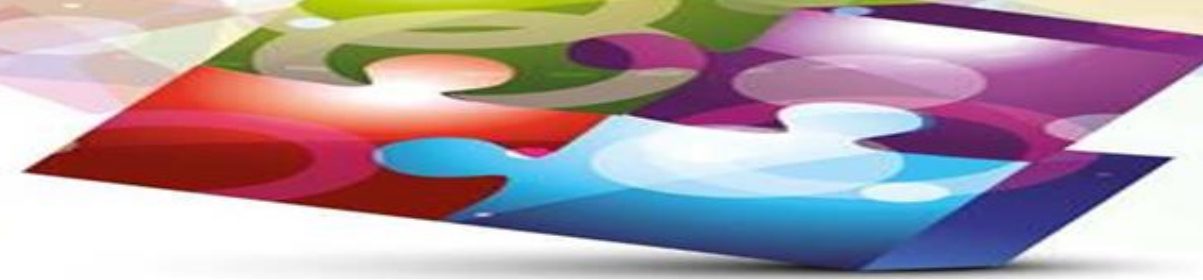

teria acesso aos mesmos; ii) permite a observação não apenas de comportamentos, mas também de atitudes, opiniões, sentimentos, além de superar a problemática do efeito observador.

Para Lorenzato e Fiorentini (2012, p.108) A “observação participante” é uma estratégia que envolve não só a observação direta, mas todo o conjunto de técnicas metodológicas (incluindo entrevistas, consulta a materiais etc.), pressupondo um grande envolvimento do pesquisador na situação estudada.

Os registros das observações foram realizados com o auxílio de um diário de campo, esse é um instrumento em que o observador registra as ações observadas quando estava inserido no meio pesquisado.

Fiorentini e Lorenzato (2012) afirmam que:

[...] o diário é um dos instrumentos mais ricos de coleta de informações durante o trabalho de campo. É nele que o pesquisador registra observações de fenômenos, faz descrições de pessoas, cenários e episódios, e, até transcrições de alguns diálogos. Quanto mais próximo do momento da observação for feito o registro, maior será a acuidade da informação (FIORENTINI; LORENZATO, 2012, p. 118-119).

Na pesquisa também utilizamos a análise de dados buscando relacionar os dados obtidos com a teoria utilizada. Lüdke e André (1986) apontam que "a análise documental pode se constituir em uma técnica valiosa de abordagem de dados qualitativos, seja complementando as informações obtidas por outras técnicas, seja desvelando aspectos novos de um tema ou problema" (Ibid., p. 38).

As próximas duas seções se destinam a abarcar os aportes teóricos do nosso artigo: a Teoria da Aprendizagem Significativa e a Modelagem Matemática.

\section{Teoria da Aprendizagem Significativa (TAS)}

As diversas pesquisas de David Ausubel estão concentradas principalmente no aprendizado que acontece dentro da sala de aula, dando conta das relações estabelecidas entre um novo conhecimento com as ideias anteriores dos educandos (conhecimentos prévios), assim essa teoria identifica como acontece essa organização de ideias e as suas relações. 


\section{HORIZONTES - REVISTA DE EDUCACÃ̃O}

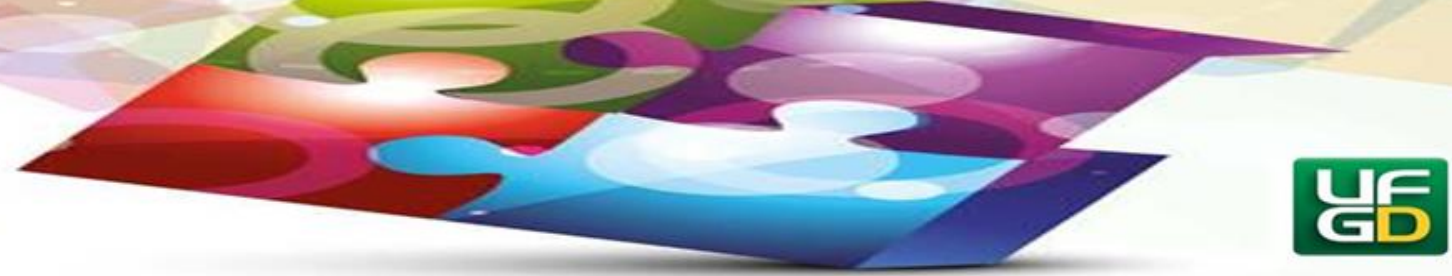

Moreira (2010) ressalta que o conhecimento prévio não deve ser confundido com a matéria ou conteúdo ensinado anteriormente, o conhecimento prévio é todo e qualquer conhecimento significativo internalizado na estrutura cognitiva do aluno.

A teoria de Ausubel é uma teoria construtivista, pois tem como característica explicar como é formado o novo conhecimento estruturado em conhecimentos anteriores do aluno. Assim, nessa teoria, o aprendiz é um sujeito, protagonista do seu próprio processo de aprendizagem, alguém que vai produzir a transformação que gera conhecimento próprio.

Para Ausubel e outros (1980), essa construção, pelo aprendiz, não se dá por si mesma e no vazio cognitivo, mas a partir de situações em que ele possa agir sobre o objeto de seu conhecimento, pensar sobre ele e buscar as respostas da sua vivência.

Assim esse autor classifica dois tipos de aprendizagem: i) a mecânica, que é a aprendizagem na qual não ocorre um diálogo lógico e claro entre as novas ideias e as já existentes na estrutura cognitiva do sujeito, ou seja, há uma interação não substantiva e literal entre o novo conhecimento e conceitos subsunçores da estrutura cognitiva do aprendiz e ii) a significativa, em que o sujeito consegue estabelecer relação substantiva e não arbitraria entre o novo conhecimento e os conhecimentos que ele já tem.

Para ocorrer a aprendizagem significativa eficazmente em um indivíduo, são necessárias duas condições segundo Moreira (1999):

a) a participação ativa do aluno no aprender: se o indivíduo quiser memorizar o material e nunca de modo não arbitrário e literal, então haverá aprendizagem mecânica;

b) a importância do material escolhido não arbitrário ser potencialmente significativo: o significado lógico depende somente da natureza do material, e o significado psicológico é uma experiência que cada indivíduo tem. Cada aprendiz deve fazer essa varredura dos materiais apontando o que tem significado ou não para si próprio (Ibid., p. 154).

A essas condições, a partir de experiências já realizadas se pode acrescentar uma terceira: c) a presença de conceitos subsunçores específicos, para que o novo conceito seja ancorado.

Por conseguinte, para Ausubel e outros (1980), o desafio do professor nessa teoria é propor situações na qual o aluno consiga pôr em jogo os seus conhecimentos e aprenda significativamente o novo saber. Os autores Moreira e Buchweitz (1993) esclarecem que essa aprendizagem significativa ocorre quando há um diálogo da nova informação com os 


\section{HORIZONTES - REVISTA DE EDUCACÃ̃O}

e-ISSN: 2318-1540

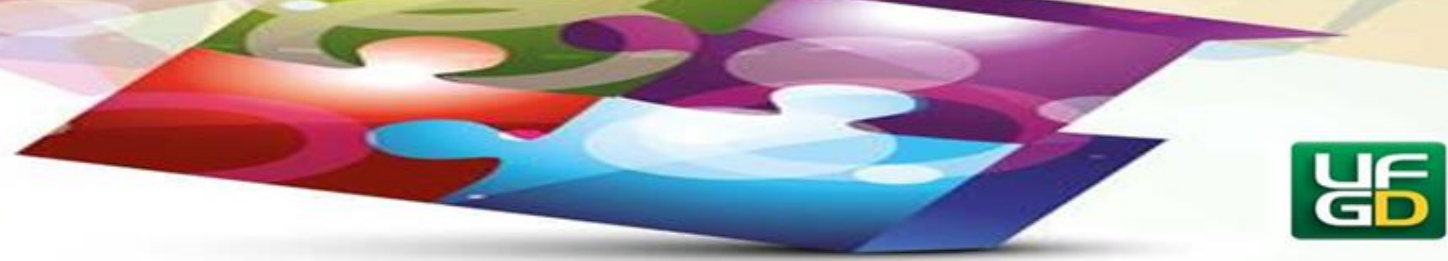

subsunçores, ancorando em conceitos e proposições relevantes, que já fazem parte da estrutura cognitiva do educando. Os subsunçores são as bases de uma aprendizagem significativa, ou seja, os seus conhecimentos relevantes, já estabelecidos na estrutura, nos quais serão ancorados os novos conhecimentos.

Assim, a TAS indica que para aprender alguma coisa é preciso já saber alguma coisa, logo o conhecimento não é gerado do nada, é uma permanente transformação a partir do conhecimento existente (MOREIRA; BUCHWEITZ, 1993).

Com isso, à medida que o aprendiz vai aprendendo um conceito, esse vai se tornando cada vez mais elaborado, mais diferenciado, em consequência da ancoragem de novos aspectos, ao mesmo tempo torna-se capaz de servir de âncora para a atribuição de significados a outros conhecimentos. Este processo característico da dinâmica da estrutura cognitiva é denominado diferenciação progressiva (MOREIRA; BUCHWEITZ, 1993).

Ausubel e outros (1980) advertem que para aprender um conceito, esse deve ser relacionável com um conceito já estabelecido na estrutura cognitiva do aprendiz, mas pode ocorrer que esses conceitos não sejam suficientes para o sujeito aprender o novo conceito. Neste caso, o professor deve criar situações para fazer uma ponte cognitiva entre o que o aluno sabe e o que deveria saber para assimilar o novo conceito.

Essa ponte cognitiva é chamada pelo autor de organizador prévio do conhecimento, que pode ser um texto introdutório ao assunto, uma atividade ou uma sequência didática, desde que consiga ajudar o aluno a relacionar os conhecimentos novos com os antigos. Vale ressaltar que esse organizador não substitui os conhecimentos necessários para aprender o novo conceito; assim se o aprendiz não tiver os conhecimentos necessários o novo conceito não é aprendido de forma significativa.

Tendo apresentado esses conceitos básicos, essenciais para a compreensão das análises que desenvolveremos. Na próxima seção abordaremos a Modelagem Matemática

\section{Modelagem Matemática}

A Modelagem Matemática pode ser compreendida como uma metodologia de ensino que possibilita ao estudante abordar conteúdos matemáticos a partir de fenômenos de sua realidade, e tem como objetivo explicar matematicamente situações do cotidiano, das mais 


\section{HORIZONTES - REVISTA DE EDUCAÇÃO}

diferentes áreas da Ciência, com o propósito de educar matematicamente. Ela permite uma inversão do "modelo comum" de ensino, visto que, por meio da Modelagem Matemática selecionam-se primeiramente os problemas e deles emergem os conteúdos matemáticos, de modo a resolvê-los (BURAK, 1992).

No entender de Bassanezi (2015), a Modelagem Matemática consiste na arte de transformar problemas da realidade em problemas matemáticos e resolvê-los interpretando suas soluções na linguagem do mundo real.

$\mathrm{Na}$ prática docente, percebemos que a Modelagem Matemática tem como principal característica, levar o estudante a assimilar conhecimentos matemáticos a partir de situações reais. No entanto, há diferentes concepções sobre como aplicar a Modelagem Matemática no ensino. Para Bassanezi (2015) e Burak (1992), os estudantes devem escolher os temas geradores e o professor a partir dessas escolhas, deve ajudar os estudantes a buscar as soluções matemáticas para o problema escolhido. Para Beltrão (2009) e Sadovsky (2010), a escolha do tema pelos alunos pode dificultar na medida em que na escola há um programa para seguir.

De acordo com Burak (1992) e Bassanezi (2015), a escolha do tema que vai gerar a construção de um modelo matemático deve ser atribuição dos alunos. Para isso, o conjunto de conhecimentos prévios deve orientar o caminho a seguir nesse processo de construção. Em contraposição, Beltrão (2009), assumindo aspectos de sua prática, indica que os conhecimentos prévios, o prazo fixado previamente para construir o programa do curso e as exigências da instituição se constituem em obstáculos para frutificarem as orientações de deixar ao encargo do aluno a escolha do tema no processo de Modelagem Matemática.

Embora haja essa diferença entre a atribuição da escolha do fenômeno, há convergência para o entendimento que, a Modelagem Matemática tem como característica, promover que o estudante busque as soluções dos problemas a partir de seus conhecimentos prévios, mobilizando diferentes conhecimentos para criar estratégias de resolução, avaliação e reflexão sobre o problema estudado.

Nesse sentido, a Modelagem Matemática pode ser compreendida como uma boa estratégia de aprendizagem, visto que ela pressupõe o ensino de conceitos matemáticos a partir dos conhecimentos dos alunos, entendemos assim que a modelagem é um suporte perfeito para a teoria da aprendizagem significativa. 


\section{HORIZONTES - REVISTA DE EDUCAÇÃO}

e-ISSN: 2318-1540

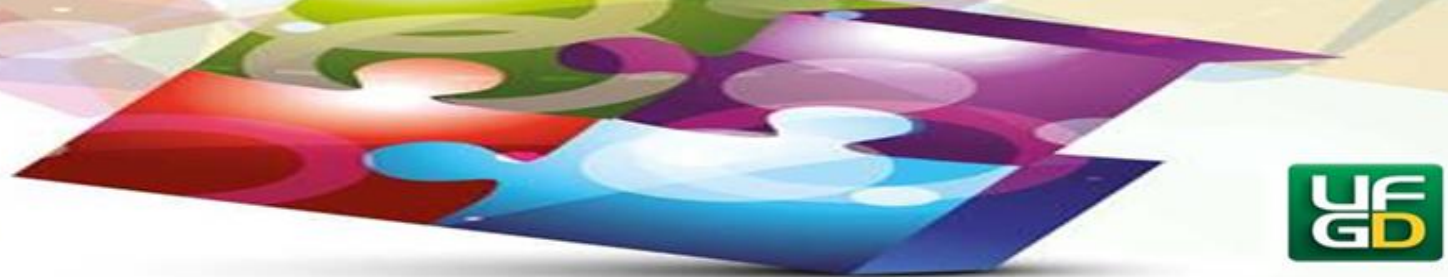

A seguir traremos as atividades e suas respectivas analises, além de trazer os protocolos dos alunos.

\section{A Sequência Didática e analise dos resultados}

A sequência didática desenvolvida é composta de oito atividades e elas foram desenvolvidas a partir dos dados que os alunos obtiveram ao medir o comprimento da sombra de uma haste no decorrer de um dia. Essa aconteceu em dois dias no período das 8:00 às 15:30, em que os alunos mediam o comprimento da sombra a cada trinta minutos.

Essa atividade foi uma proposta do professor da turma que também é o primeiro autor deste trabalho, como explicitado anteriormente, tínhamos por objetivo fazer com que os alunos percebessem que a sombra no decorrer de dois ou mais dias realiza um movimento repetitivo e a partir dessa analise trabalharíamos o conceito de função tangente.

Nessa perspectiva adotamos a sequência com o pressupostos da Modelagem Matemática como organizador prévio do conhecimento, ou seja, o aluno a partir de seus dados e logo de suas análises concretas construiria o novo conhecimento.

Para Moreira (1999) o organizador prévio é qualquer (objeto/ação) que visa facilitar a aprendizagem de um novo conhecimento.

Assim começamos a sequência após a realização das medidas por parte dos alunos (Figura 1).

Figura 1: Obtenção de dados
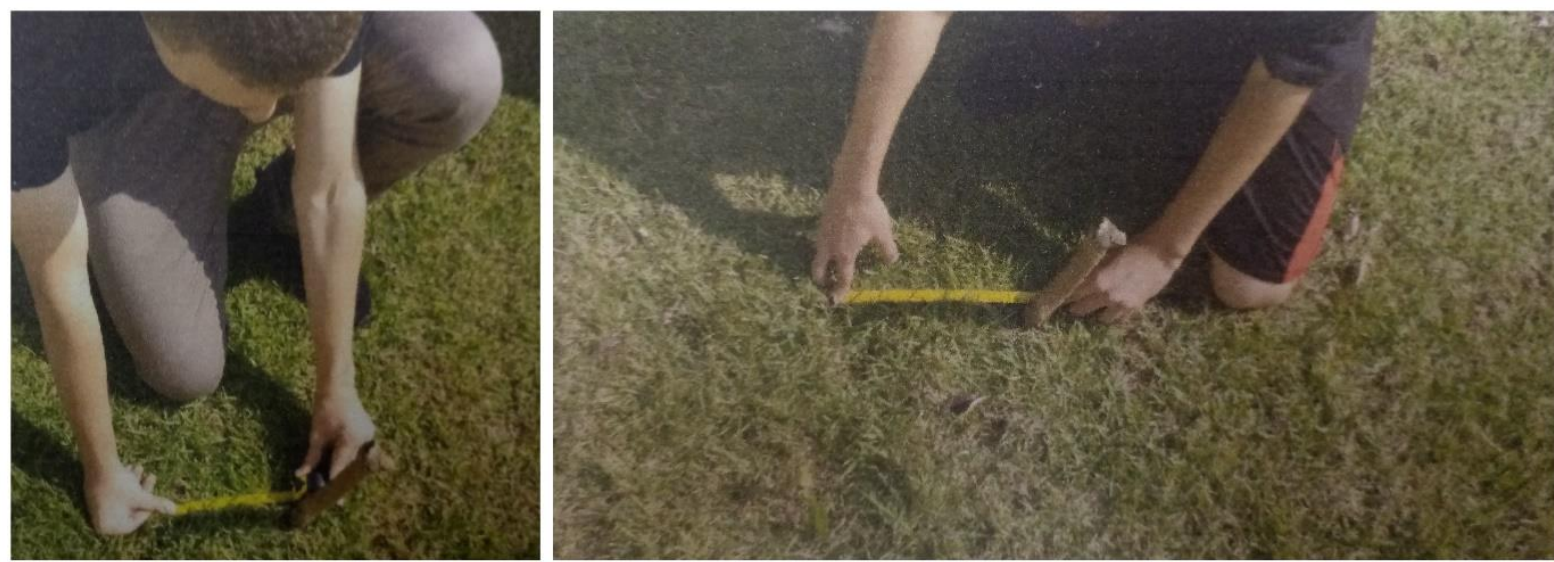

Fonte: Produção nossa. 


\section{MORIZONTES - REVISTA DE EDUCAÇÃO}

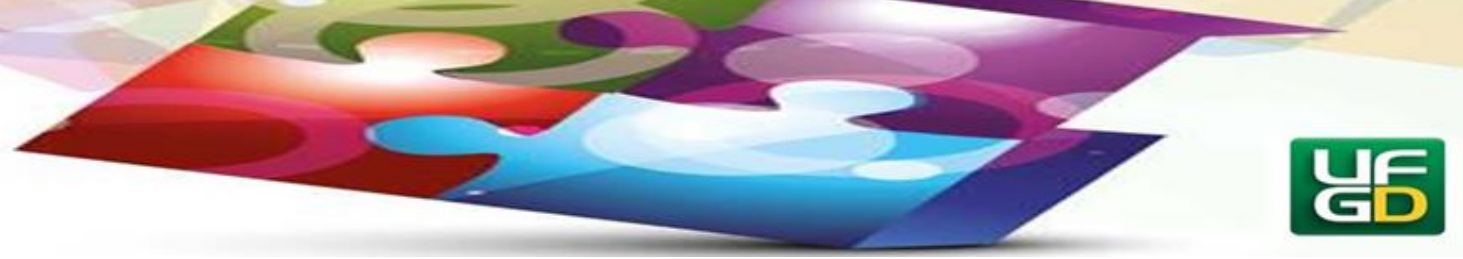

Com posse dessas medidas foi pedido que os alunos em grupo realizassem a sequência, em que na atividade um era pedido para que eles colocassem os comprimentos das medidas e o horário da realização da mesma (Figura 2).

Figura 2: Protocolo dos Alunos

\begin{tabular}{|c|}
\hline A partir dos dados obtidos complete a tabela. \\
\hline $1^{\circ} \mathrm{DIA}$ \\
\hline Horário $\quad 830 \quad 9: 00993010: 00103011: 0011: 30$ 12:00 $123013: 00133014: 00143015001530$ \\
\hline Comprimento $48 \mathrm{~cm} 36 \mathrm{~cm} 30 \mathrm{~cm} 21 \mathrm{~cm} 20 \mathrm{~cm} 19 \mathrm{~cm} 15 \mathrm{~cm} 12 \mathrm{~cm} 13 \mathrm{~cm} 14 \mathrm{~cm} 17 \mathrm{~cm} 24 \mathrm{~cm} 25 \mathrm{~cm} 28 \mathrm{~cm} 29 \mathrm{~cm}$ \\
\hline $2^{\circ} \mathrm{DIA}$ \\
\hline 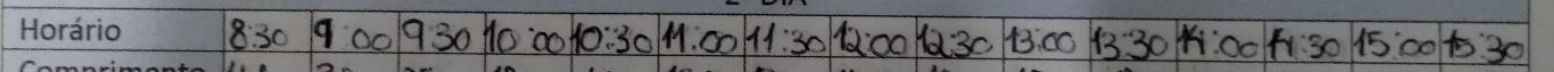 \\
\hline Comprimento $41 \mathrm{~cm} 32 \mathrm{~cm} 25 \mathrm{~cm} 18 \mathrm{~cm} 17 \mathrm{~cm} 13,513 \mathrm{~cm} 14,514 \mathrm{~cm} 15 \mathrm{~cm} 18 \mathrm{~cm} 25 \mathrm{~cm} 27 \mathrm{~cm} 29 \mathrm{~cm}$ vinas \\
\hline
\end{tabular}

Fonte: Produção nossa.

$\mathrm{Na}$ atividade dois, os alunos deveriam colocar os valores registrados na tabela da atividade um no plano cartesiano e após isso indicar o par ordenado no plano em cada medição, para essa ação consideramos que os alunos já tinham conhecimentos prévios suficientes sobre pares ordenados e plano cartesiano, como um dos autores era professor da turma tinha condições de saber aquilo que os alunos já dominavam de conceitos matemáticos.

No decorrer da segunda atividade o professor tomou como referência os pressupostos da Observação Participante e Teoria da Aprendizagem Significativa, ou seja, o professor deve conduzir a aula de modo a fazer com que os alunos consigam aprender significativamente o novo conhecimento.

Wilkinson (1995) entende que na observação participante o observador não é apenas um expectador, nesse sentido, ele faz parte do contexto que é analisado. Já Ausubel (1976) classifica que no processo da aprendizagem significativa o professor deve criar situações de modo que o aprendiz consiga aprender significativamente, nesse sentido entendemos que o professor deva auxiliar a aquisição de conhecimentos por parte dos alunos.

Assim nessa atividade todos os grupos responderam da mesma forma (Figura 3), apenas um dos grupos fez uma representação diferente (Figura 4). 


\section{MORIZONTES - REVISTA DE EDUCAÇÃO}

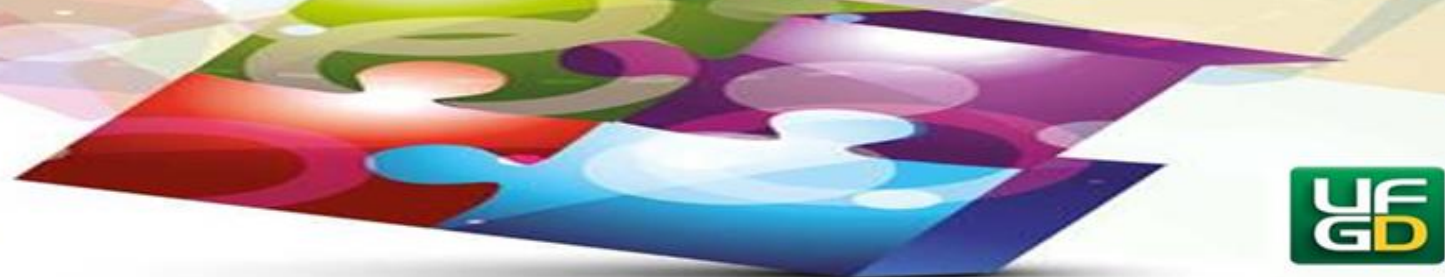

Figura 3: Protocolo dos Alunos

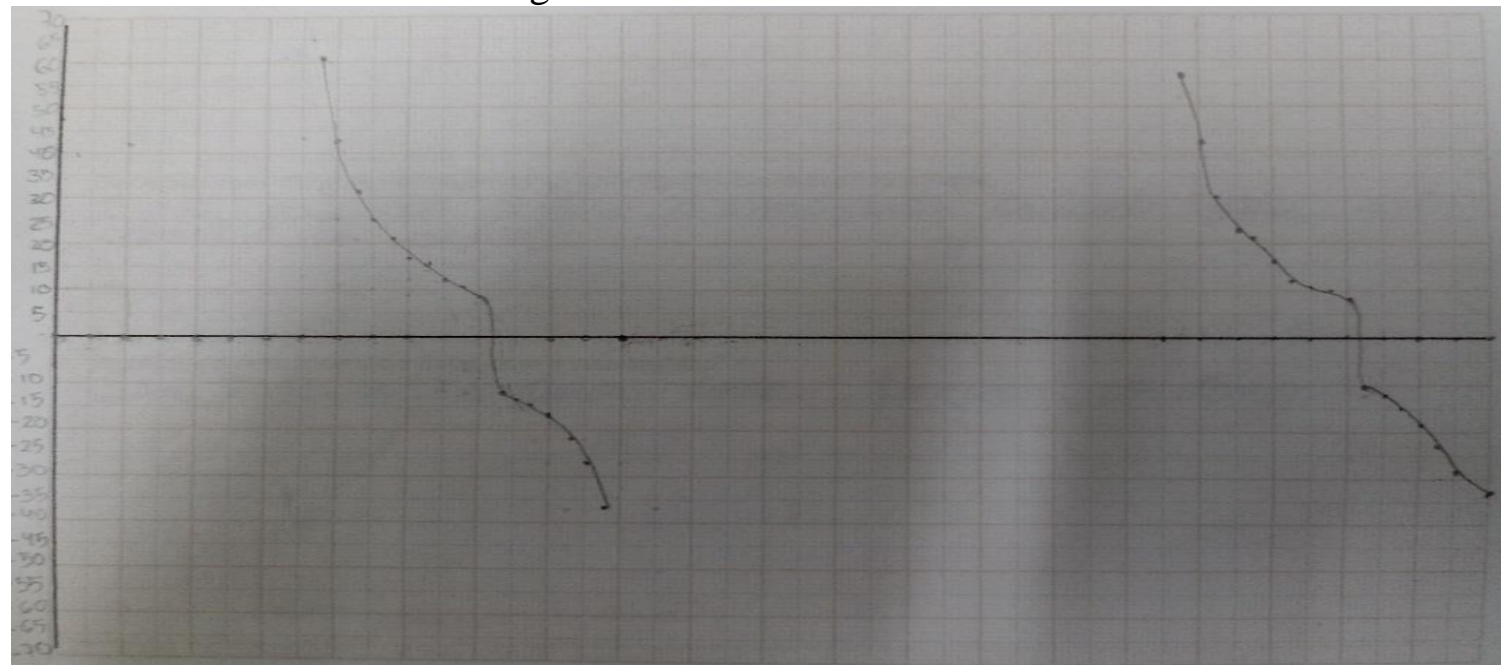

Fonte: Produção nossa.

Eles demonstraram entendimento que após um certo horário a sombra muda de posição, deste modo o valor do comprimento deveria ser representado na parte negativa do eixo das ordenadas, logos os grupos entendem conceitos de deslocamento.

Cabe ressaltar que os alunos ligaram os pontos das coordenada as tonando uma função continua e nesse caso é uma função discreta, na pratica docente percebemos que esse é um erro comum nos estudantes, sendo necessário que o professor faça interversões para explicar as diferenças entre as funções discretas e continuas.

Figura 4: Protocolo dos Alunos

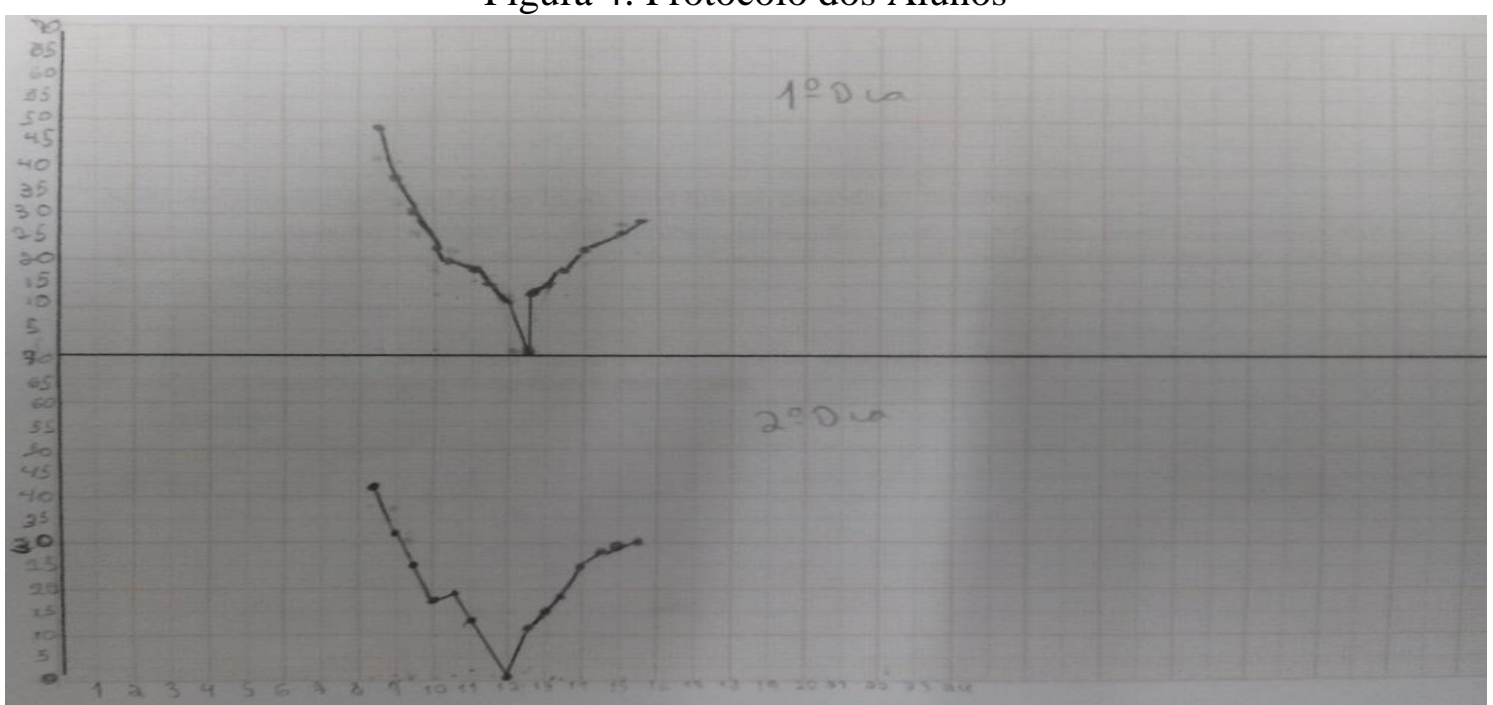

Fonte: Produção nossa. 


\section{MORIZONTES - REVISTA DE EDUCAÇ̃̃O}

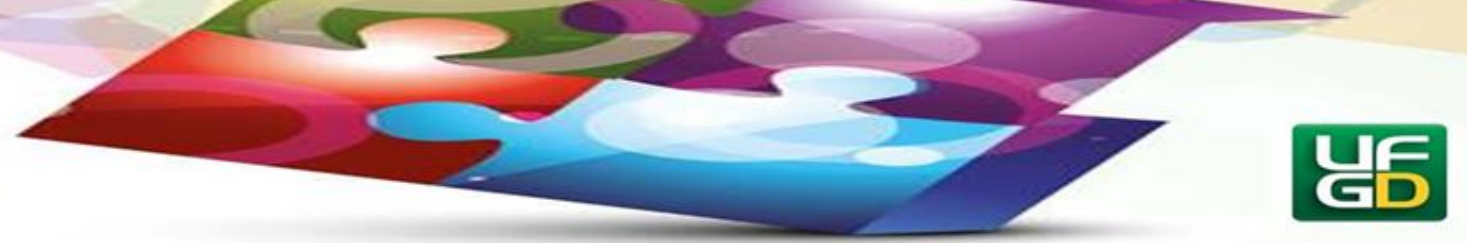

Esse grupo diferente dos outros grupos parecem não ter entendimento de deslocamento, logo não fizeram diferença entre o deslocamento da sombra entre uma direção e outra, poderíamos pensar que eles levaram o modulo dos valores, mas por ser professor da turma o pesquisador essa hipótese foi descartada. Para Ausubel (1976) no processo da aprendizagem significativa alguns conceitos não são consolidados na estrutura cognitiva do aprendiz sendo muitas vezes necessário realizar uma ponte cognitiva entre o que o aluno sabe e o que deverá saber, assim o professor pode realizar um organizador prévio para essa ação.

Em outra atividade era pedido que eles descrevessem o comportamento do comprimento da sombra antes e depois do período pesquisado, queríamos perceber se eles entendiam que só existem sombra nos períodos com a luz do Sol e que ao nascem e ao se pôr a sombra tende ao infinito. Compreendemos que na Teoria da Aprendizagem Significativa o professor deve propor boas situações de aprendizagem, assim é necessário pensar nas possíveis respostas dos alunos para que possamos fazer boas intervenções no processo da aprendizagem. Os cinco grupos pesquisados informaram que as sombras seriam maiores nesses períodos, e apenas um grupo informa que as tenderiam ao infinito seja no pôr ou nascer do sol. Segue alguns protocolos.

Figura 5: Protocolo dos Alunos

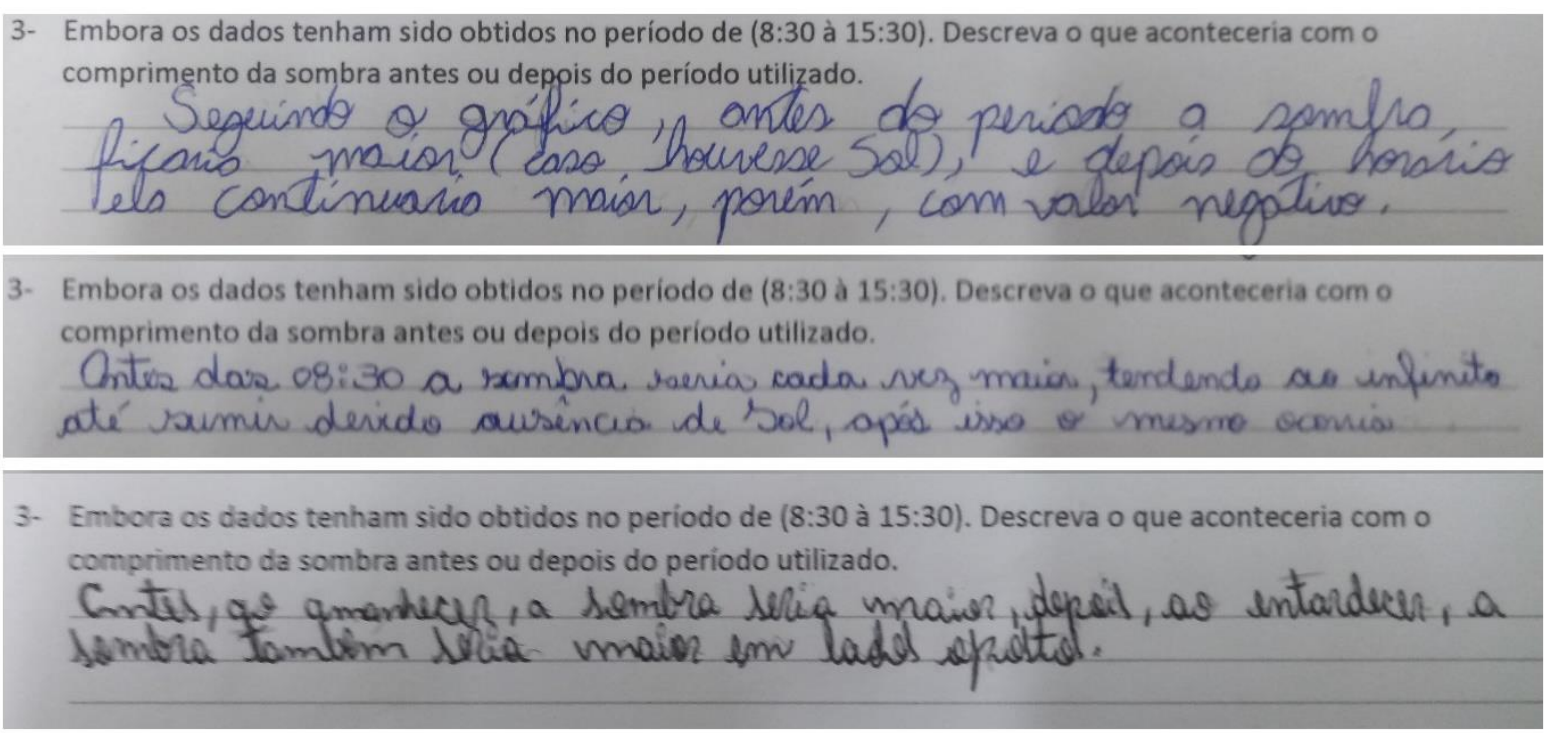

Fonte: Produção nossa.

Pelos protocolos foi perceptível que essa atividade foi significativa, pois os alunos demostram entendimento do comprimento da sombra, acreditamos que isso se deve Pelo fato 


\section{MORIZONTES - REVISTA DE EDUCAÇÃO}

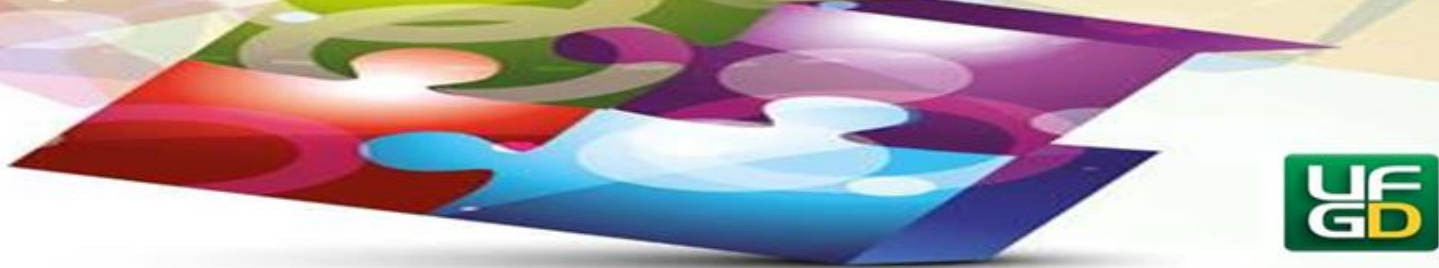

das atividades serem desenvolvida com base na Modelagem Matemática, pois nesse processo os alunos vivenciam o saber matemático, percebendo a presença desse saber nas situações diárias.

Burak (1992) já descrevia que no processo da Modelagem Matemática o aluno muda a maneira de aprender matemática partindo do fenômeno para o conceito matemático, diferente do modelo normalmente utilizado que parte do conceito para o fenômeno.

A próxima atividade perguntava como seriam os gráficos se eles tivessem feito essa ação por mais dias e todos os grupos informaram que seriam semelhantes, ou seja, não seriam iguais, e alguns descrevem que essa não igualdade é gerada pelos movimentos de translação e rotação da terra.

Figura 6: Protocolo dos Alunos
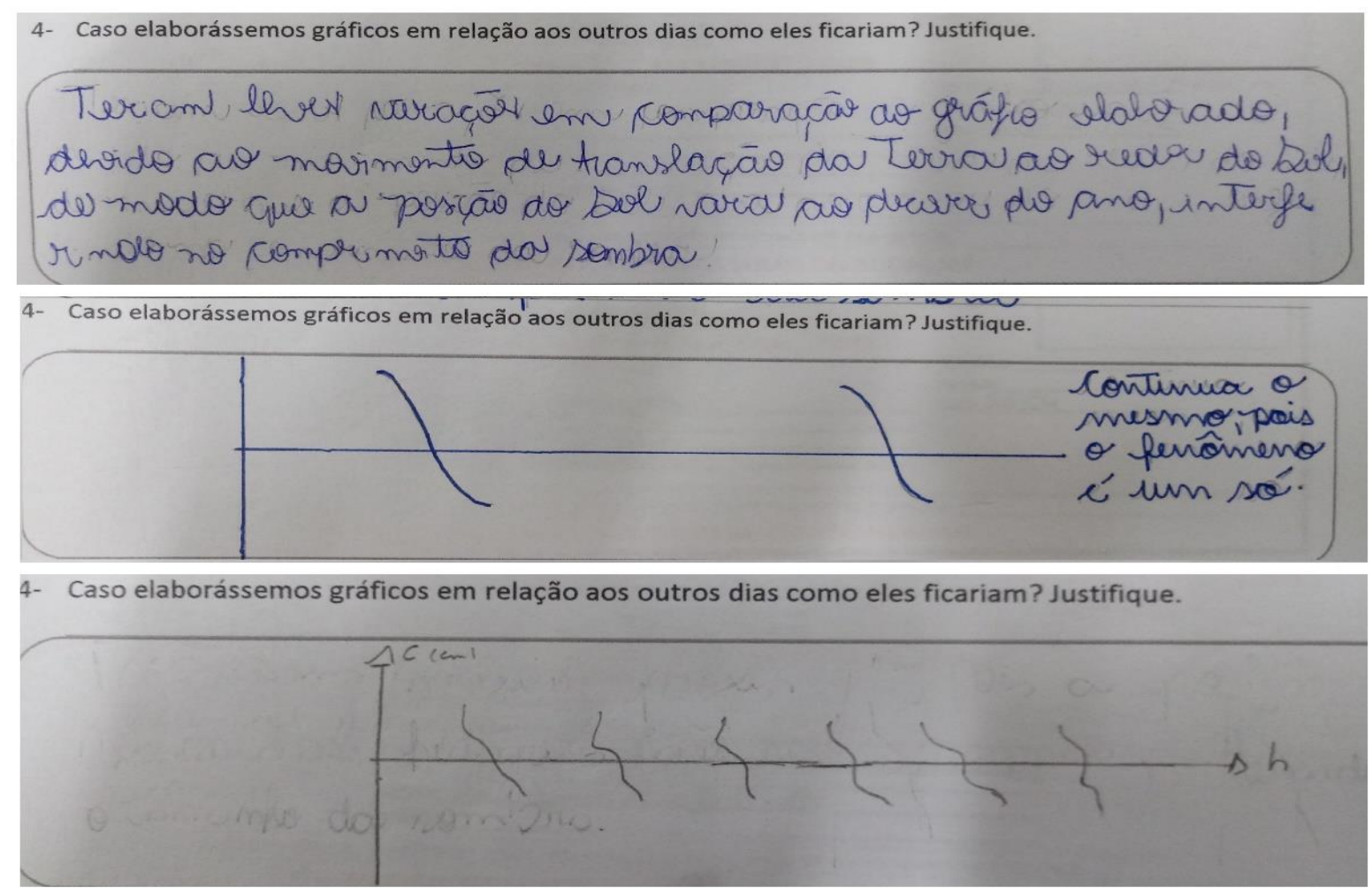

Fonte: Produção nossa.

É importante destacar que ao realizar a Modelagem Matemática o aluno é levado a uma matemática real e não a uma situação ideal. Barbosa (2001) diz que é comum livros textos trazer exercícios em que os alunos trabalham fenômenos, e em muitos deles vemos situações de polias 


\section{MORIZONTES - REVISTA DE EDUCAÇ̃̃O}

e-ISSN: 2318-1540

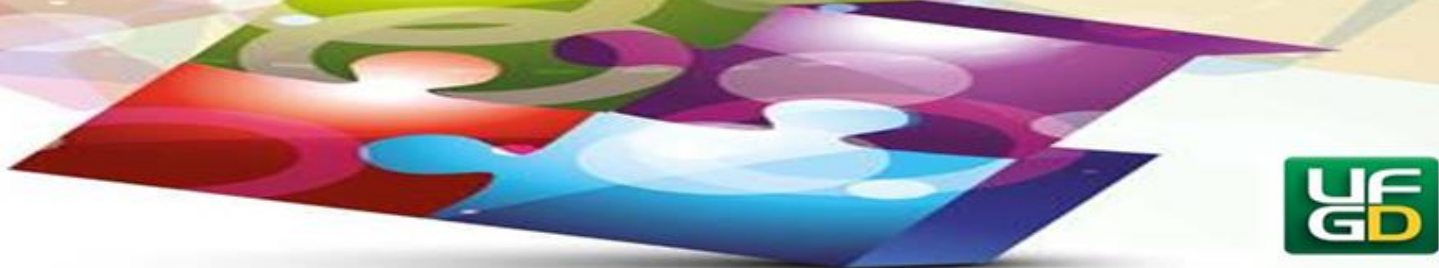

sem atrito, queda livre sem resistência do ar e etc. Logo trabalhamos fenômenos que não tem nenhuma relação com a realidade. Com a Modelagem Matemática podemos trabalhar e fenômeno real e explicar que as "fórmulas matemáticas" são "ajustes para a compreensão matemática".

As atividades 5, 6 e 7 tratam de perguntar se os grupos conseguem identificar o domínio e imagem da função e dizer se a mesma é periódica, conforme vemos nas outras respostas eles já demonstravam que tinham esse entendimento, quando dizem que a sobram tende ao infinito (imagem), que se repete (função periódica) e que a sombra inicia no nascer do sol e finaliza ao pôr do sol (domínio). Mesmo que eles não consigam colocar o rigor matemático é perceptível que eles entendem o fenômeno. Assim traremos as respostas da atividade 8, em que era objetivado que os alunos fizessem uma relação entre as funções periódicas conhecidas (seno, cosseno e tangente) e a função construída por eles.

A atividade buscava que eles percebessem que esse movimento da sobram é uma "derivação" da função tangente. Segue os protocolos.

Figura 7: Protocolo dos Alunos

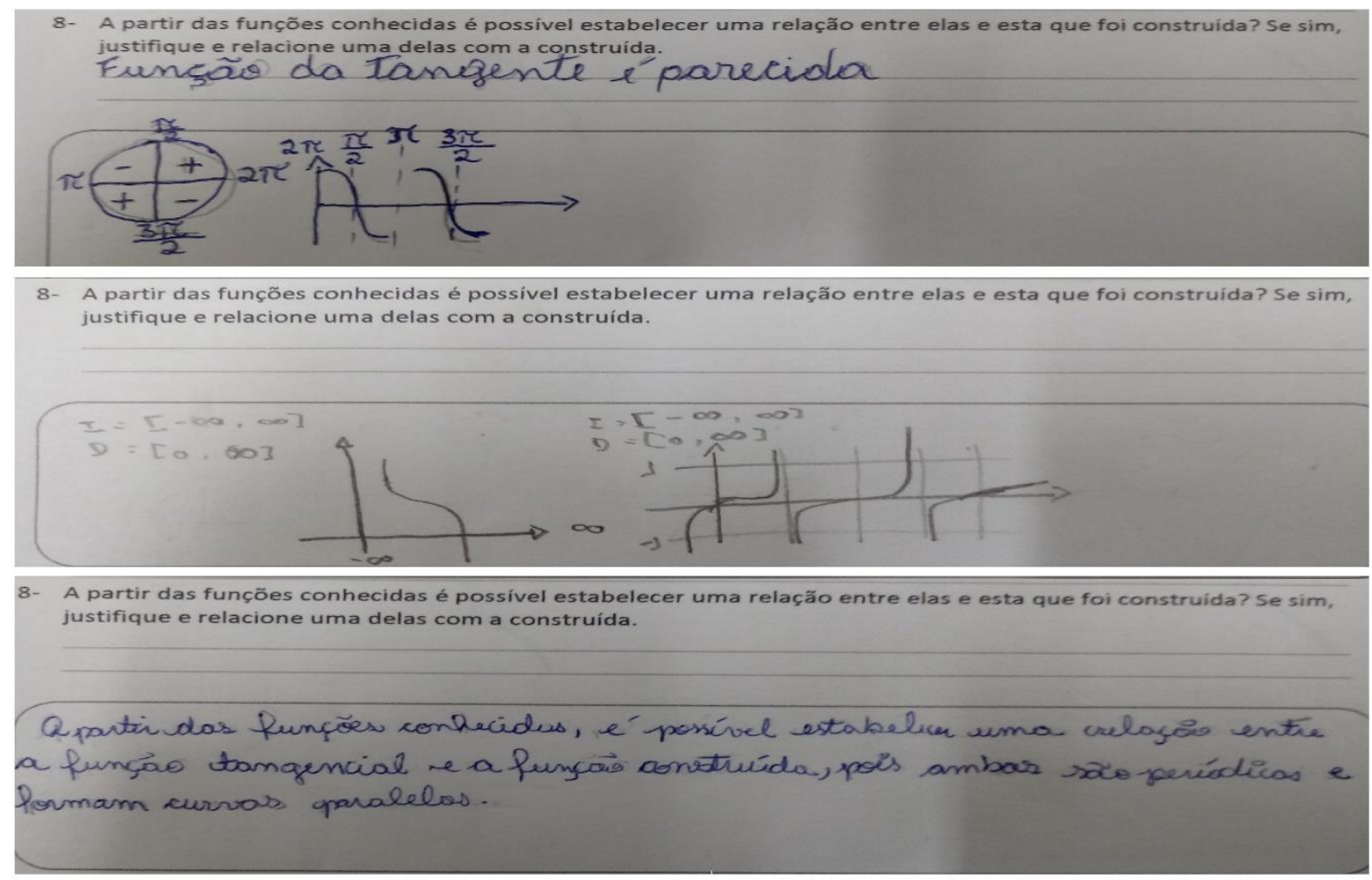

Fonte: Produção Nossa.

Horizontes - Revista de Educação, Dourados-MS, v. 5, n. 10, p. 114-130, jul./dez. 2017. Faculdade de Educação (FAED) da Universidade Federal da Grande Dourados (UFGD) 


\section{HORIZONTES - REVISTA DE EDUCAÇÃO}

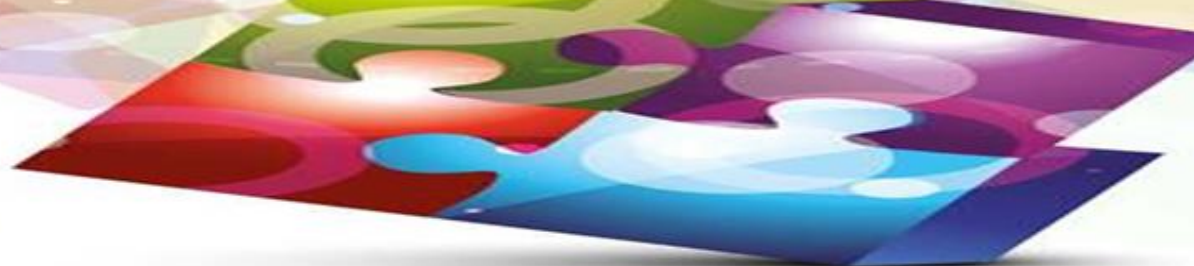

Percebemos que todos os grupos foram capazes de responder significativamente esta atividade, pois descrevem que a função construída pode ser aproximada por uma função tangente e ainda apresentam gráficos da função tangente para validar as suas respostas.

\section{Considerações Finais}

A partir do nosso estudo conseguimos concluir que a articulação entre a Teoria da Aprendizagem Significativa e a Modelagem Matemática foi eficaz, pois os alunos no decorrer das atividades foram colocando seus conhecimentos em jogo e adquirindo novos conhecimentos.

Percebemos também que uma sequência de atividades desenvolvidas com base em pressupostos da Modelagem Matemática pode ser um organizador prévio para a aprendizagem de funções trigonométricas, pois faz com que os alunos saiam de situações concretas (dados obtidos por eles) e construam os saberes matemáticos.

Percebemos também que a Modelagem Matemática é muito mais profunda do que chegar a uma relação matemática, ou seja, utilizando-a desenvolvemos uma aproximação do estudo da função tangente e essa foi suficiente para envolver os alunos que participaram das atividades no aprendizado das funções trigonométricas percebendo que essas funções podem ser visualizadas em diversas situações.

Finalmente a partir do exposto podemos dizer que na situação estudada com o grupo estudado chegamos em uma aprendizagem significativa.

\section{Referências}

AUSUBEL, D.P.; NOVAK, J.D.; HANESIAN, H. Educational psychology. New York: Holt, Rinehart and Winston. Publicado em português. Rio de Janeiro: Editora Interamericana,, 1980 .

BARBOSA, J. C. Modelagem na Educação Matemática: contribuições para o debate teórico. In: Anais... 24a Reunião Anual da Anped. Caxambu-MG: ANPED, 2001. CD-ROM.

BASSANEZI, R. C. Modelagem Matemática: teoria e prática. São Paulo: Contexto, 2015. 


\section{HORIZONTES - REVISTA DE EDUCACÃ̃O}

e-ISSN: 2318-1540

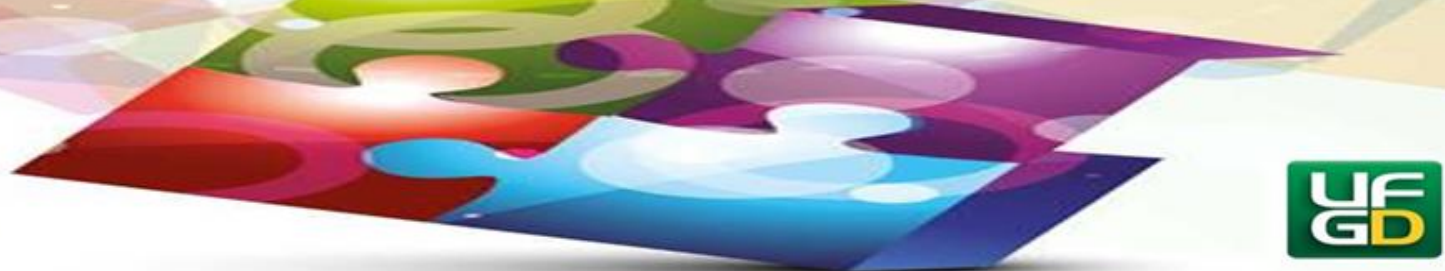

BELTRÃO, M. E. P. Ensino de cálculo pela Modelagem Matemática e aplicações: teoria e prática. 2009. 323f. Tese (Doutorado em Educação Matemática) - Faculdade de Ciências Exatas e Tecnologia. Pontifícia Universidade Católica de São Paulo. São Paulo, 2009.

BRASIL. Parâmetros Curriculares Nacionais: Matemática. Secretaria de Educação Fundamental. Brasília: MEC/SEF, 1998.

BRASIL. Base Nacional Comum Curricular. Secretaria de Educação Fundamental. Brasília: MEC/SEF, 2017.

BURAK, D. Modelagem matemática: ações e interações no processo de ensino aprendizagem. 1992. Tese (Doutorado em Educação) - Faculdade de Educação. Universidade Estadual de Campinas. Campinas, 1992.

COSTA, F. A. O ensino de funções trigonométricas com o uso da modelagem matemática sob a perspectiva da teoria da aprendizagem significativa. 2017. 142 f. Dissertação (Metrado em Educação Matemática) - Pontifícia Universidade Católica de São Paulo. São Paulo, 2017.

LUDKE, M.; ANDRÉ, M. E. D. A. Pesquisa em educação: abordagens qualitativas. São Paulo: E.P.U., 1986.

MOREIRA, M. A. Aprendizagem significativa. Brasília: Editora da UnB, 1999.

MOREIRA, M. A.; BUCHWEITZ, B. Novas estratégias de ensino e aprendizagem: os mapas conceituais e o Vê epistemológico. Lisboa: Plátano Edições Técnicas. 1993.

MOREIRA, M. A. Mapas conceituais e aprendizagem significativa. São Paulo: Centauro Editora, 2010.

SANTOS, R. F. O uso da modelagem para o ensino da função seno no ensino médio. 2014. Dissertação (Mestrado em Educação Matemática) - Pontifícia Universidade Católica de São Paulo. São Paulo, 2014.

SADOVSKY, P. O ensino da Matemática hoje: enfoques, sentidos e desafios. São Paulo: Ática, 2010.

Enviado 08/08/2018

Aceito 29/08/2018 